\title{
Adhesion to Primary and Permanent Dentin and a Simple Model Approach
}

\author{
Deniz C. Can-Karabulut ${ }^{a}$ \\ Firdevs Tulga $\mathrm{Oz}^{\mathrm{b}}$ \\ Baris Karabulut ${ }^{c}$ \\ Inci Batmaz ${ }^{d}$ \\ Ozlem Ilke
}

\section{ABSTRACT}

Objectives: First to compare different dentin bonding agents' shear bond strength to primary and permanent dentin. Secondly to compare the fracture failure modes and making an attempt to develop a statistical model that could be helpful in predicting them.

Methods: Extracted human primary and permanent molars were used as substrates (dentin). The shear bond strength of composite to substrate was measured and fracture surfaces were evaluated visually and with stereomicroscope. Using the data obtained, a statistical model was built in order to predict the failure modes.

Results: Higher bond strength values were obtained for permanent dentin. Total-etch adhesives displayed higher shear bond strength values than the self-etch adhesive. Adhesive failures were more frequently seen in primary dentin. Self-etch adhesive system displayed more adhesive failures. Prepared model confirmed the negative relationship between shear bond strength and the probability of observing adhesive failure.

Conclusions: There should be an application protocol for the usage of dentin bonding agents in primary dentin. Further development of statistical and fuzzy models for failure modes can be supportive alternatives for microscopic evaluations and also be helpful in understanding and eliminating the factors which are responsible for the formation of adhesive failures and for achieving clinically more successful adhesive restorations. (Eur J Dent 2009;3:32-41)

Key words: Adhesive restorations; Failure modes; Primary dentin; Shear bond strength test.

a PhD, Department of Operative Dentistry, Faculty of Dentistry, Near East University, Mersin, Turkey.

b Professor, Department of Pediatric Dentistry, Faculty of Dentistry, University of Ankara, Ankara, Turkey.

c PhD, Department of Pediatric Dentistry, Faculty of Dentistry, University of Ankara, Ankara, Turkey.

d Associate Professor, Department of Statistics, Art and Sciences Faculty, Middle East Technical University, Ankara, Turkey. e PhD, Department of Statistics, Art and Sciences Faculty, Middle East Technical University, Ankara, Turkey.

Corresponding author: Dr. Deniz C. Can-Karabulut Department of Operative Dentistry,

Faculty of Dentistry, Near East University, Mersin 10, Turkey.

Phone:+90 $3926802030 / 2618$

Fax: +903926802025

E-mail: cdenizcankayahoo.com 


\section{INTRODUCTION}

Dental bonding materials form a bond between tooth structure and the restorative materials. This formed adhesive bond will provide protection of the tooth structure during restoration and will lengthen the restorations' clinical lifetime. ${ }^{1}$ Different classifications can be made including dentin bonding agents' clinical application types, their effect mechanisms and contents. ${ }^{2}$ There is less information about dentinal adhesion to primary dentin when compared with permanent dentin. ${ }^{3}$ One of the laboratory tests which guide clinicians in restorative materials' clinical usage are bond strength tests. The most commonly used ones are tensile and shear bond strength tests. ${ }^{4}$ Failures are classified as adhesive, cohesive and mixed types. ${ }^{5}$ Al-Salehi and Burke ${ }^{4}$ had reported that there was a relationship between the bond strength and fracture failure mode. There are various shear bond strength studies reporting failure modes using different methodologies mostly by microscopic methods in literature. ${ }^{6,7}$ The first aim of this study was to compare different dentin bonding agents' bond strength to primary and permanent dentin using shear bond strength test. Second aim was to compare the failure modes with a stereomicroscope, to put an effort to develop a statistical model that could be helpful to establish the relationship between the shear bond strength values and failure modes and to study whether developing this kind of a statistical model for evaluation of failure modes would be a beneficial method. This kind of approach has not been conducted in the literature. A statistical model that could be helpful in estimating the possibility of obtaining an adhesive type of fracture when a certain amount of shear bond strength was applied was aimed to be developed.

Further development of statistical models for failure modes can be supportive alternatives for microscopic evaluations and also be helpful in understanding and eliminating the factors which are responsible for the formation of adhesive failures and for achieving clinically more successful adhesive restorations.

\section{MATERIALS AND METHODS}

21 extracted, caries-free, unrestored primary second molars and 21 extracted caries-free, unrestored erupted permanent third molars were used in this study. Any remaining soft tissues were thoroughly hand-scaled and cleaned from the tooth surfaces and teeth were disinfected in $0.5 \%$ chloramine solution and placed in distilled water for up to 1 month at $-20^{\circ} \mathrm{C}$. Crowns were separated from the roots $2-3 \mathrm{~mm}$ apical from the cementoenamel junction (CEJ), and pulp tissue was removed with a dental explorer. After this procedure crowns were embedded into teflon molds vertically by using a self-curing acrylic resin (Orthocryl EQ, Dentaurum, Germany). The mid-coronal dentin of the occlusal surfaces was exposed by a flat cut perpendicular to the long axis of the tooth with a fine diamond disc in high speed with a copious water spray and 300 , 600 grit-SiC paper were used to prepare a flat dentin surface on the specimens and to simulate the dentin smear layer formed after clinical instrumentation. After the dentin surfaces had been controlled for the absence of enamel with a stereomicroscope (Leica, MZ 12, Leica AG, CH9435 Heerbrugg, Switzerland) both primary and permanent molars were randomly divided into three groups respectively.

Dentin bonding agents were applied according to the manufacturers' instructions. Before the applications an adhesive tape with a central orifice of $3 \mathrm{~mm}$ in diameter was applied to the dentin surfaces to demarcate the area to be treated. Different dentin bonding agents were applied to each subgroup. In Group I, a three-step total-etch (Scotchbond Multi Purpose (SBMP)), in Group 2, a two-step total-etch IGluma Comfort Bond (GCB)l and in Group 3, a one-step self-etch (Adper Prompt-L-Pop (PLP)) system were used. Information regarding dentin bonding agents is presented in Table 1. A halogen light curing unit (Hilux 200, Benlioglu Dental Inc, Ankara, Turkey) with a light intensity of $400 \mathrm{~mW} / \mathrm{cm}^{2}$ was used in order to light cure the applied bonding agents. This light curing unit was controlled with a radiometer (Curing Radiometer, Model 100, Demetron/Kerr Corp. Danbury, USAl during the experiment.

After the application of dentin bonding agents, a resin composite material (Z100 Restorative A2, 3M ESPE, St Paul, MN, USA) was applied on to the prepared dentin surfaces with the help of a teflon tube with an inner diameter of $3 \mathrm{~mm}$ and a height of 
$2 \mathrm{~mm}$ which was carefully attached to the prepared and previously delimitated dentin surfaces by an impression putty mould. Composite materials were light cured for a total of $160 \mathrm{~s} ; 40$ seconds from each perpendicular direction by using the same halogen light curing unit. After curing had been completed the Teflon tube surrounding the composite was carefully removed. All specimens were stored in distilled water at $37^{\circ} \mathrm{C}$ for 24 hours. After this period, samples were subjected to thermal cycling at $5-55^{\circ} \mathrm{C}$ for 500 cycles with a dwell time of 30 s. 24 hours after thermal cycling, specimens were debonded using an universal testing machine (Lloyd LRX Universal, Lloyd Instruments, Fareham, Hants, EnglandUK) at a crosshead speed of $0.5 \mathrm{~mm} / \mathrm{min}$ at room temperature $\left(23 \pm 2^{\circ} \mathrm{C}\right)$. The specimens were secured in a mounting jig (Bencor Multi-T shear assembly, Danville Engineering Inc., San Ramon, CA) with the shearing rod against and parallel to the flat prepared bonding sites. The distance from the probe to the dentin surface was monitored using a spacer of two celluloid matrices. The specimens were stored in water, except for the period of testing. Shear bond strengths were calculated by dividing the highest fracture force $(\mathrm{N})$ with the bonded area (diameter $3 \mathrm{~mm}$ ) and recorded in MPa. After the application of shear bond strengths to resin-dentin bonded surfaces and specimens were debonded, failure modes were recorded. For this purpose debonded areas were examined visually for their failure region and were also observed under a stereomicroscope (Leica, MZ 12, Leica AG, CH-9435 Heerbrugg, Switzerland) at $25 x$ magnification to evaluate the site of failure. The actual mode of failure was recorded according to the following criteria: ${ }^{5}$

Adhesive failure mode: No signs of dentin fracture or remnants of resin on the tooth, failure in adhesion.

Cohesive failure mode: Complete fracture of dentin or resin, failure of the tooth substrate or failure of the resin composite.

Mixed failure mode: Samples showing both

Table 1. Manufacturers, name codes, classifications, ingredients and applications of dentin bonding agents.

\begin{tabular}{|c|c|c|}
\hline $\begin{array}{l}\text { Dentin Bonding Agent, Batch } \\
\text { Number, Manufacturer, Name } \\
\text { Code and Classification }\end{array}$ & $\begin{array}{l}\text { Ingredients of the Bonding } \\
\text { Agent }\end{array}$ & Application of the Bonding Agent \\
\hline $\begin{array}{l}\text { Scotchbond Multi Purpose } \\
\text { Adhesive; LOT 3NB } \\
\text { Primer; LOT 3AE } \\
\text { 3M ESPE, St Paul, MN, USA } \\
\text { SBMP } \\
\text { 3-step total-etch adhesive }\end{array}$ & $\begin{array}{c}\text { Etchant: } 35 \% \text { phosphoric acid } \\
\text { etchant } \\
\text { Primer: HEMA, polyalkenoic } \\
\text { acid } \\
\text { Adhesive: BIS-GMA, HEMA }\end{array}$ & $\begin{array}{l}\text { Etching: Apply Scotchbond etchant. Wait } 15 \\
\text { seconds. } \\
\text { Rinse for } 15 \text { seconds. Dry for } 2 \text { seconds. Apply } \\
\text { Scotchbond Multi-Purpose primer to etched } \\
\text { enamel and dentin. Dry gently for } 5 \text { seconds. } \\
\text { Apply Scotchbond Multi-Purpose adhesive and } \\
\text { light-cure for } 10 \text { seconds. }\end{array}$ \\
\hline $\begin{array}{l}\text { Gluma Comfort Bond } \\
\text { LOT } 010035 \\
\text { Heraeus-Kulzer, Dormagen, } \\
\text { Germany } \\
\text { GCB } \\
\text { 2-step total-etch adhesive }\end{array}$ & $\begin{array}{l}\text { Etchant: } 20 \% \text { phosphoric acid } \\
\text { Adhesive: UDMA, HEMA, } \\
\text { 4-META, } \\
\text { maleic acid, polycarboxylic } \\
\text { acid ester, } \\
\text { ethanol, water, photoinitiators }\end{array}$ & $\begin{array}{l}\text { Apply GLUMA Etch } 20 \text { gel to the entire cavity } \\
\text { surface and leave for } 20 \text { seconds. Rinse and } \\
\text { remove excess moisture from the preparation } \\
\text { with a gentle stream of air for } 1 \text { - } 2 \text { seconds. } \\
\text { Apply the adhesive wait and light cure for } 20 \\
\text { seconds. }\end{array}$ \\
\hline $\begin{array}{l}\text { Adper Prompt-L-Pop } \\
\text { LOT } 141438 \\
\text { 3M ESPE, St Paul, USA } \\
\text { PLP } \\
\text { 1-step self-etch adhesive }\end{array}$ & $\begin{array}{c}\text { Liquid } 1 \text { (Red blister): } \\
\text { Methacrylated phosphoric } \\
\text { esters, Bis-GMA, initiators } \\
\text { based on camphorquinone. } \\
\text { Liquid } 2 \text { (Yellow blister): } \\
\text { Water, } \\
\text { 2-Hydroxyethyl } \\
\text { methacrylate,polyalkenoic acid } \\
\text { copolymer, stabilizers. }\end{array}$ & $\begin{array}{l}\text { Brush the adhesive onto entire cavity surface. } \\
\text { Massage it in for } 15 \text { seconds. Blow air on the } \\
\text { adhesive until it becomes a thin film. The } \\
\text { surface must have an even shine. Harden the } \\
\text { adhesive with a halogen or LED light for } 10 \\
\text { seconds. }\end{array}$ \\
\hline
\end{tabular}


adhesive and cohesive failures.

In the statistical analysis and modeling section, a logistic regression model was developed to explain the fracture type by the shear bond strength, and a linear regression model was built to investigate the effects of the tooth structure and the material type on the shear bond strength values.

Modeling the failure mode

Because the ordinal logistic regression models fitted mostly failed in predicting mixed type of fractures, and also because the main goal of this study was avoiding to have the worst type of fracture, the response was categorized as observing either the worst type of fracture li.e. adhesive) or observing the others (i.e. cohesive and mixed). The response, $y$, was set to one if the fracture type was 'adhesive'; it was set to zero if the fracture type was either 'cohesive' or 'mixed'. Several binary logistic models were fit by using SPSS $15^{8}$ and compared by classification rates and goodness-of-fit measures. ${ }^{9}$ The best model finally obtained was:

$\hat{P}(y=1 I X)=\exp \left(-0.547-0.34 x_{c}\right) /\left(1+\exp \left(-0.547-0.34 x_{c}\right)(1)\right.$

where $x_{c}$ is the centralized shear bond strength value, i.e., $x_{c}=x-x$. For each possible observed value of centered strength, one can calculate the estimated probabilities. If the estimated probability of observing adhesive type fracture is greater than 0.5 , the response was classified as 'adhesive'. For this model, a true classification rate of $(1-10 / 41) 100 \%=75.6 \%$ was obtained. This means that, about $76 \%$ of all observations were classified into the correct response categories. Summary statistic based on deviance residuals ( $P$ value $=0.46)$ and Hosmer-Lemeshow goodnessof-fit ( $P$ value $=0.628$ ) test showed no lack-offit. In short, by the use of this model, one can estimate the possibility of obtaining an adhesive type of fracture when a certain amount of shear bond strength is applied.

\section{Modeling the shear bond strength}

To express the change in the shear bond strength values with respect to the tooth structure and the material type, a linear regression model in (2) was developed by using the statistical software SPSS $15 .^{8}$

$$
x=\beta_{0}+\beta_{1} z_{1}+\beta_{2} z_{2}+\beta_{3} z_{3}+\beta_{4} z_{1} z_{2}+\beta_{5} z_{1} z_{3}+\beta_{6} z_{2} z_{3}+e . \text { (2) }
$$

In this model, $x$ is the response representing the shear bond strength values measured in $\mathrm{MPa}$. The indicator variable $z_{1}$ represents the levels of the 'tooth structure'. Similarly, two other indicator variables, denoted by $z_{2}$ and $z_{3}$, represent the levels of the 'material type'. How treatment groups (tooth structure, material type) were represented by different codings of these indicator variables is presented in Table 2. To illustrate, the second row of the table, where $z_{1}=1, z_{2}=0, z_{3}=1$, indicates the treatment group in which the dentin bonding agent PLP was applied to the primary dentin.

To obtain statistically valid results, it is important that the white noise assumption is satisfied. However, the analysis of residuals from the fitted model (2) indicated that both constant error variance and normality assumptions were violated. As a remedial measure, the power l=0.5 was applied to the response, $x$, as suggested by the Box-Cox power transformation. ${ }^{10} \mathrm{Graphical}$ analysis of residuals after transformation of the response, $x$, indicated that the white noise

Table 2. Different codings of the indicator variables for representing the levels of qualitative variables (i.e. treatment groups).

\begin{tabular}{llll}
\hline Treatment groups (tooth structure, material type) & $\mathbf{z}_{1}$ & $\mathbf{z}_{2}$ & $\mathbf{z}_{3}$ \\
\hline (Primary, GCB) & 1 & 1 & 0 \\
(Primary, PLP) & 1 & 0 & 1 \\
(Primary, SBMP) & 1 & 0 & 0 \\
(Permanent, GCB) & 0 & 1 & 0 \\
(Permanent, PLP) & 0 & 0 & 1 \\
(Permanent, SBMP) & 0 & 0 & 0 \\
\hline
\end{tabular}


assumption was satisfied. The resultant model consisting of only statistically significant lall $P$ values $<0.015$ ) model parameters is given in (3).

$\hat{w}=0.205+0.0388 z_{1}+0.0837 z_{3}+0.0126 z_{1} z_{2}-0.0269 z_{1} z_{3}$, where $\hat{w}=x^{-0.5}$.

\section{RESULTS}

The ANOVA table for ( 3 ) is presented in Table 3. The minimum, maximum and the mean shear bond strength values measured in Newton and MPa along with their standard deviations for all groups are presented in Table 4. Besides, recorded failure modes as percentages are given in Table 5. Note that the percentages were calculated by dividing the count in a cell by the number of observations in each subgroup. To exemplify, 2 out of 7 primary teeth where SBMP was applied turned out to be adhesive failure mode. As a result, 28.57 (=2/7) \% of the primary teeth were adhesive.

Depending on the descriptive statistics calculated (Tables 4 and 5) and the models developed in the 'statistical analysis and modeling' section for both shear bond strength values and failure modes, the following results were obtained; tooth type affected the shear bond strength test values ( $P$ value $=0.0)$; there was a statistically significant difference in primary and permanent dentin except the self-etch adhesive system (PLP) ( $P$ value $=0.0$ ). Higher bond strength values were obtained for permanent dentin. For primary and permanent dentin mean strength values were 14.36 MPa and 19.57 MPa, respectively. Material type also affected the shear bond strength test values ( $P$ value $<0.015)$. Total-etch adhesives displayed higher shear bond strength values than the self-etch adhesive both in primary and permanent dentin. Mean strength values for the total-etch adhesives (SBMP and GCB) were 15.99 $\mathrm{MPa}$ and $23.35 \mathrm{MPa}$ for primary and permanent dentin, respectively. Mean strength values for the self-etch adhesive (PLP) were 11.09 MPa and 12.01 MPa, for primary and permanent dentin, respectively. Although there was no statistical difference between total-etch adhesives (P value $>0.05$ ), three-step total-etch system had given slightly higher shear bond strength results compared to the two-step one both in permanent and primary dentin. Mean strength values for three-step total-each system (SBMP) were 16.79 $\mathrm{MPa}$ and $23.48 \mathrm{MPa}$ for primary and permanent dentin, respectively. Whereas mean strength values for two-step one (GCB) were $15.19 \mathrm{MPa}$ and 23.23 MPa for primary and permanent dentin, respectively. When the results were evaluated it was observed that adhesive failures were more frequently seen in primary dentin; while the

Table 3. The ANOVA table for the equation (3).

\begin{tabular}{|c|c|c|c|c|c|}
\hline Resource & Degrees of Freedom & Sum of Squares & Mean Square & $\mathrm{F}$ & P-value \\
\hline Regression & 4 & 0.055224 & 0.013806 & 163.89 & 0.0 \\
\hline Error & 36 & 0.003033 & 0.000084 & & \\
\hline Total & 40 & 0.058256 & & & \\
\hline
\end{tabular}

$\mathrm{s}=0.00917804 \mathrm{R} 2=94.8 \%$ R2(Adjusted) $=94.2 \%$

Table 4. Descriptive statistics of the shear bond strength values (Newton and MPa) for all groups.

\begin{tabular}{|c|c|c|c|c|c|c|}
\hline \multirow[b]{2}{*}{ Teeth Type } & \multirow{2}{*}{$\begin{array}{l}\text { Dentin } \\
\text { Bonding } \\
\text { Agents }\end{array}$} & \multirow[b]{2}{*}{$\mathrm{n}$} & \multirow[b]{2}{*}{$\begin{array}{c}\text { Mean SBS } \\
\text { (Newton) }\end{array}$} & \multicolumn{3}{|c|}{ Shear Bond Strength (MPa) } \\
\hline & & & & Mean $\pm S D$ & Min & Max \\
\hline \multirow{3}{*}{ Primary Teeth } & SBMP & 7 & 118.74 & $16.79 \pm 0.70$ & 15.84 & 17.72 \\
\hline & GCB & 7 & 107.43 & $15.19 \pm 0.82$ & 14.09 & 16.51 \\
\hline & PLP & 7 & 78.45 & $11.09 \pm 0.97$ & 9.79 & 12.62 \\
\hline \multirow{3}{*}{ Permanent Teeth } & SBMP & 7 & 165.97 & $23.48 \pm 1.95$ & 20.12 & 26.00 \\
\hline & GCB & 7 & 164.26 & $23.23 \pm 3.33$ & 17.12 & 26.76 \\
\hline & PLP & 7 & 84.89 & $12.01 \pm 0.85$ & 10.81 & 13.33 \\
\hline
\end{tabular}


adhesive failure ratio was $38.12 \%$ in permanent dentin, this ratio was $52.38 \%$ in primary dentin. It had also been observed that the self-etch adhesive system (PLP) displayed more adhesive failures compared to the total-etch adhesives (SBMP and GCB) both in permanent and primary dentin. While the adhesive failure ratio for selfetch adhesive system was $85.72 \%$ and $71.53 \%$ for primary and permanent dentin, respectively; this ratio for total-etch adhesives was $35.71 \%$ and $21.42 \%$ for primary and permanent dentin, respectively.

\section{DISCUSSION}

In this study shear bond strength test results of primary and permanent dentin were statistically different from each other for total-etch adhesives. Higher bond strength values were obtained for permanent dentin compared to primary dentin. This result is in consistence with some of the previous studies which had reported that this lower bond strength values in primary teeth were related with the physical, micromorphological and chemical differences between primary and permanent teeth. ${ }^{5,11-15}$ Nör et al ${ }^{14}$ indicated in their study that the hybrid layer produced was significantly thicker in primary than in permanent teeth, suggesting that primary tooth dentin was more reactive to acid conditioning. According to these authors, the increased thickness of the hybrid layer in primary teeth and the subsequent lack of complete penetration of adhesive resin into previously demineralized dentin may contribute to the lower bond strengths to primary dentin. Shorter time for dentin conditioning could be used as a means to reproduce the hybrid layer thickness seen in permanent teeth.

Material types also affected the shear bond strength test results. Total-etch adhesives displayed higher shear bond strength values than the self-etch adhesive both in primary and permanent dentin. In literature some studies had reported that self-etch systems did not display adequate bond strength. ${ }^{16-20}$ On the other hand, there are other studies supporting these systems. ${ }^{21-23}$ According to Bolanos-Carmona et $\mathrm{a}^{24}$ the performance of self-etching adhesives on primary dentin depends on the product. Van Meerbeek et al ${ }^{25}$ concluded that in spite of enhanced ease and faster application, simplified adhesives so far seem to induce a loss of bonding effectiveness, and their advantages should therefore be traded off against their shortcomings. Nevertheless, in the end the only true criterion for an adhesive's quality had been reported as its long-term clinical performance. ${ }^{25}$

Although there was no statistical difference between total-etch adhesives, three-step totaletch system had given slightly higher shear bond strength results compared to the two-step one both in permanent and primary dentin. Although this difference could be due to chance for this

Table 5. Counts and percentages of failure modes in permanent and primary dentin.

\begin{tabular}{|c|c|c|c|}
\hline Teeth $n=7$ & $\begin{array}{c}\text { Adhesive } \\
\text { Failure Mode (\%) }\end{array}$ & $\begin{array}{l}\text { Cohesive } \\
\text { Failure Mode in Dentin }(\%)\end{array}$ & $\begin{array}{c}\text { Mixed } \\
\text { Failure Mode (\%) }\end{array}$ \\
\hline \multirow{2}{*}{ Primary/ SBMP } & 2 & 1 & 4 \\
\hline & (28.57) & (14.28) & $(57.14)$ \\
\hline \multirow{2}{*}{ Primary/ GCB } & 3 & 1 & 3 \\
\hline & (42.85) & (14.28) & (42.85) \\
\hline \multirow{2}{*}{ Primary/ PLP } & 6 & - & 1 \\
\hline & (85.72) & & (14.28) \\
\hline \multirow{2}{*}{ Permanent/ SBMP } & 1 & 2 & 4 \\
\hline & (14.28) & (28.57) & (57.14) \\
\hline \multirow{2}{*}{ Permanent /GCB } & 2 & 2 & 3 \\
\hline & (28.57) & (28.57) & (42.85) \\
\hline \multirow{2}{*}{ Permanent /PLP } & 5 & - & 2 \\
\hline & (71.53) & & (28.57) \\
\hline
\end{tabular}


study, some of the researches had reported that despite the simplification studies which were trying to lesser the application steps of the bonding systems, conventional 3-step adhesive systems were the most reliable systems currently. ${ }^{26-29}$

It was found that the adhesive failure ratio in permanent dentin was lower than in primary dentin. In another saying adhesive failures were more frequently seen in primary dentin. This result was consistent with the shear bond strength test values indicating that bonding to permanent dentin was more successful compared to primary dentin. When the results were considered from the material type; it had been observed that the selfetch adhesive system displayed more adhesive failures compared with the total-etch adhesives both in permanent and primary dentin supporting the shear bond strength test's results as it had been found lower shear bond strength values for the self-etch group like the corroborating studies. ${ }^{12,30,31}$ According to the results of this study separate applications of each step by threestep adhesive system enhances the efficacy and also provides the necessary time for the bonding material to penetrate into dentin tubules.

But it should be taken into account as Leloup et $\mathrm{al}^{32}$ concluded in their study that many parameters like the test design and experimental conditions significantly influence dentin bond strength. In this study, the extracted teeth were stored in distilled water at $-20^{\circ} \mathrm{C}$, like ${ }^{33,34}$ which had stated that this was the preferred method for testing the bond strength of resin composites to dentin. According to the studies $33,35,36$ dentin adhesives tend to function well in bond strength tests when tested shortly after application. Price and $\mathrm{Hall}^{5}$ reported that they had found significant differences between fracture failure modes obtained 10 minute and 24 hour after the application of the bonding systems. In this study samples were subjected to thermal cycling 24 hours after the restorative procedures and to shear bond strength test 24 hours after thermal cycling. Studies had reported that in vitro bonding tests were effective methods in understanding the physical strength of adhesive systems, and were also, important tools in predicting and developing the clinical performance of these systems..$^{31,37,38}$ By these efforts, conservation of the tooth structure and lengthening the clinical lifetime of the restorations can be obtained. ${ }^{39}$ Researchers ${ }^{40,41}$ had mentioned that the advantage of this in vitro measurement of bond strength test method was being relatively simple with respect to specimen preparation, equipment required and test setup, but the main criticism was that it measured the cohesive strength of the material being bonded or the substrate (or both), rather than the bond strength of the adhesive interface. Also studies ${ }^{42-47}$ reported that despite its well known limitations the shear bond test set up had been the most commonly employed laboratory technique for evaluating the bond strength of adhesives and resin-bonded restorations but a notable feature of the studies evaluating shear bond strength tests was the observation that the failure mode was predominantly cohesive within the substrate and that this was attributed to the nature of the stresses generated and their distribution within the adherence zone and the relatively low bond strengths obtained might be explained by differences in material combinations, test set up and operator factors. Finally, Windley et al ${ }^{48}$ stated that though in vitro bond strength tests did not directly predict clinical performance, the comparisons between groups were valid and could be utilized when making clinical decisions.

Failure modes had been classified as adhesive, cohesive and mixed. ${ }^{5}$ Triolo and Swift ${ }^{49}$ and Mason et $a l^{50}$ had thought that in weaker adhesive systems, fracture type was adhesive and minimal resin penetration occurred in these systems. They had reported that cohesive type was seen with stronger systems. Perdigao et $\mathrm{al}^{51}$ had similarly observed and reported that, cohesive type of fractures were begun to be seen when the shear bond strength values exceeded 17.40 $\mathrm{MPa}$. Similarly cohesive type of failures were observed when the shear bond strength values exceeded 16.5 MPa for primary dentin and 24.9 $\mathrm{MPa}$ for permanent dentin in this study. It had been estimated that bond strengths of 17 to 20 MPa may be required to resist contraction forces sufficiently to produce gap-free restoration margins. ${ }^{52}$ Researchers ${ }^{28,53,54}$ observed that the adhesive failures between dentin and the bonding system occurred in lower bond strength values and studied the probable factors for this in their research study. There are also other researchers supporting the idea that failure types were not 
correlated with bond strength values especially in cohesive type of failures in dentin. ${ }^{13,42,55,56}$ Cohesive type of failure in dentin is an important issue which should be studied in detail in a different study. But in this study it had been concluded that, statistical investigation of failure types could be beneficial if the limitations could be eliminated in further studies and the results obtained supported the results of bond strength test values. Al Quahtani et $\mathrm{al}^{53}$ also reported a corroborating result and mentioned that investigation of failure types could provide important data in the analysis of the results of shear bond strength values and that the classification of failure modes was an important observation.

In short, within the limitations of this in vitro study, bonding to permanent dentin was found to be more successful compared to primary dentin. This can be due to various factors including both the structural differences between tooth structures and the applied materials. Another important factor is the fact that dentin bonding agents are developed mostly by using permanent teeth. There is no application protocol that is given for the usage of dentin bonding agents in primary teeth by any of the manufacturers. For example shorter etchant application time periods can enhance adhesion by preventing excessive demineralization so can be studied and advised. Besides, new bonding agents for primary teeth can be developed. It had been found that totaletch adhesives have still got their own advantages when compared to the self-etch adhesive system. But self-etch adhesives have also got their own clinical benefits especially in patients where isolation is hard to obtain, so they worth developing with further in vivo research.

A statistical model that could be helpful in estimating the possibility of obtaining an adhesive type of fracture when a certain amount of shear bond strength was applied was aimed to be built. Developed statistical model for understanding the relationship between failure modes and the shear bond strength test values confirmed that lower bond strength values were associated with the adhesive failures. By using this model and the methodology one might predict the failure mode by substituting his/her own estimated shear bond strength data into the model and learn whether the failure mode will be adhesive or not without using a microscope. It should be emphasized here that in its present form the developed model must not be generalized and may only be applicable to the investigated adhesive systems and the laboratory method that had been used in this study. However, it can be improved in several ways in the future. For example, a further research can be conducted to investigate the mixed type and the types of cohesive failure separately. Besides, fuzzy approach can be used to model the data in order to take into consideration that failure mode evaluations are subjective, and thus, both models' prediction performances can be compared with respect to various criteria. Moreover, other applications like acid etching may also be factored in as one of the variables in modeling of failure modes. Further models developed based on studies using universal testing standards with increased sample size, different materials and variables according to the subject, will be useful for a larger group of investigators and can be helpful in estimating the possibility of obtaining an adhesive type of fracture when a certain amount of shear bond strength is applied and understanding the positive or negative role of different variables on shear bond strength of adhesives.

\section{CONCLUSIONS}

Further development of statistical and fuzzy models for failure modes can be supportive alternatives for microscopic evaluations and also be helpful in understanding and eliminating the factors which are responsible for the formation of the adhesive failures and for achieving clinically more successful adhesive restorations.

\section{REFERENCES}

1. Perdigao J. Dentin bonding as a function of dentin structure. Dent Clin North Am 2002;46:277-301.

2. Van Meerbeek B, Vargas M, Inoue S, Yoshida Y, Peumans M, Lambrechts $P$, Vanherle G. Adhesives and cements to promote preservation dentistry. Oper Dent 2001;(Suppl 6):119-144.

3. Uekusa S, Yamaguchi K, Miyazaki M, Tsubota K, Kurokawa $H$, Hosoya $Y$. Bonding efficacy of single-step self-etch systems to sound primary and permanent tooth dentin. Oper Dent 2006;31:569-576.

4. Al-Salehi SK, Burke FJ. Methods used in dentin bonding tests: An analysis of 50 investigations on bond strength. 
Quint Int 1997;28:717-723.

5. Price RB, Hall GC. In vitro comparison of 10-minute versus 24-hour shear bond strengths of six dentin bonding systems. Quint Int 1999;30:122-134.

6. Korkmaz Y, Baseren M. Effect of antibacterial varnishes applied to root dentin on shear bond strength of toothcolored restorative materials. Oper Dent 2008;33:65-71.

7. Schneider BT, Baumann MA, Watanabe LG, Marshall GW Jr. Dentin shear bond strength of compomers and composites. Dent Mater 2000;16:15-19.

8. SPSS for Windows, Rel. 15.0.1. 2006. Chicago: SPSS Inc.

9. Hosmer DW, Lemeshow Jr.S. Applied Logistic Regression, New York: Wiley, 2000.

10. Myers RH. Classical and Modern Regression with Applications. Brooks: Cole Publishing Co, 2000.

11. Sumikawa DA, Marshall GW, Gee L, Marshall SJ. Microstructure of primary tooth dentin Pediatr Dent 1999;21:439-444.

12. Agostini FG, Kaaden C, Powers JM. Bond strength of selfetching primers to enamel and dentin of primary teeth. Pediatr Dent 2001;23:481-486.

13. Araujo FB, Garcia-Godoy F, Issao M. A comparison of three resin bonding agents to primary tooth dentin. Pediatr Dent 1997; 19:253-257.

14. Nör, JE, Feigal RJ, Dennison JB, Edwards CA. Dentin bonding: SEM comparison of the resin-dentin interface in primary and permanent teeth. J Dent Res 1996;75:13961403.

15. Mazzeo N, Ott NW, Hondrum SO. Resin bonding to primary teeth using three adhesive systems. Pediatr Dent 1995;17:112-115.

16. Ibarra G, Vargas MA, Armstrong SR, Cobb DS. Microtensile bond strength of self-etching adhesives to ground and unground enamel. $J$ Adhes Dent 2002;4:115-124.

17. Öztaș N, Ölmez A. Effects of one versus two applications of a self-etching adhesive to dentin of primary teeth: a SEM study. J Contemp Dent Prac 2005;6:18-25.

18. Naughton WT, Latta MA. Bond strength of composite to dentin using self-etching adhesive systems. Quint Int 2005;36:259-262.

19. Strydom C. Self-etching adhesives: review of adhesion to tooth structure part I. SADJ 2004;59:413-419.

20. Swift EJ Jr. Dentin/enamel adhesives: review of the literature. Pediatr Dent 2002;24:456-461.

21. Christensen GJ. Self-etching primers are here. JADA 2001;132:1041-1043.

22. Bekes K, Boeckler L, Gernhardt CR, Schaller HG. Clinical performance of a self-etching and a total-etch adhesive system- 2-year results. J Oral Rehabil 2007;34:855-861.
23. Marquezan M, da Silveira BL, Burnett LH Jr, Rodrigues CR, Kramer PF. Microtensile bond strength of contemporary adhesives to primary enamel and dentin. J Clin Pediatr Dent 2008;32:127-132.

24. Bolaños-Carmona V, González-López S, De Haro-Muñoz C, Briones-Luján MT. Interfacial morphology and bond strength of self-etching adhesives to primary dentin with or without acid etching. $J$ Biomed Maters Res Part B App Biomat 2008; In press.

25. Van Meerbeek B, Van Landuyt K, De Munck J, Hashimoto M, Peumans M, Lambrechts $P$, Yoshida Y, Inoue S, Suzuki K. Technique-sensitivity of contemporary adhesives. Dent Mater J 2005;24:1-13.

26. Frankenberger R, Perdigao J, Rosa BT, Lopes M. “Nobottle" vs "multi-bottle" dentin adhesives- a microtensile bond strength and morphological study. Dent Mater 2001;17:373-380.

27. Van Meerbeek B, De Munck J, Yoshida Y, Inoue S, Vargas M, Vijay P, Van Landuyt K, Lambrechts P, Vanherle G. Buonocore memorial lecture. Adhesion to enamel and dentin: current status and future challenges. Oper Dent 2003;28:215-235

28. Courson F, Bouter D, Ruse ND, Degrange M. Bond strengths of nine current dentine adhesive systems to primary and permanent teeth. J Oral Rehabil 2005;32:296-303.

29. De Munck J, Van Landuyt K, Peumans M, Poitevin A, Lambrechts $P$, Braem M, Van Meerbeek B. A critical review of the durability of adhesion to tooth tissue: methods and results. J Dent Res 2005;84:118-132.

30. Bouillaguet S, Gysi P, Wataha JC, Ciucchi B, Cattani M, Godin C, Meyer JM. Bond strength of composite to dentin using conventional, one-step and self-etching adhesive systems. J Dent 2001;29:55-61.

31. Sensi LG, Lopes GC, Monteiro S, Baratieri LN, Vieira LC. Dentin bond strength of self-etching primers/adhesives. Oper Dent 2005;30:63-68.

32. Leloup G, D'Hoore W, Bouter D, Degrange M, Vreven J. Meta-analytical review of factors involved in dentin adherence. J Dent Res 2001;80:1605-1614.

33. Gürgan S, Kiremitci A, Cakir FY, Yazici E, Gorucu J, Gutknecht N. Shear bond strength of composite bonded to erbium:yttrium-aluminum-garnet laser-prepared dentin. Lasers Med Sci 2007;Dec 12 [Epub ahead of print]

34. Titley KC, Chernecky R, Rossouw PE, Kulkami GV. The effect of various storage methods and media on shear bond strengths of dental composite resin to bovine dentin. Arch Oral Biol 1998;43:305-311. 
35. De Munck J, Yoshida Y, Inoue S, Vargas M, Suzuki K, Lambrects P, Vanherle G. Four-year water degradation of total-etch adhesives bonded to dentin. J Dent Res 2003;82:136-140.

36. Inoue $S$, Vargas MA, Yoshida Y, Lambrects P, Vanherle G, Sano H, Van Meerbeek B. Microtensile bond strength of eleven contemporary adhesives to dentin. J Adhes Dent 2001;3:237-245.

37. Nikaido T, Kunzelmann KH, Chen H, Ogata M, Harada N, Yamaguchi S, Cox CF, Hickel R, Tagami J. Evaluation of thermal cycling and mechanical and loading on bond strength of a self-etching primer system to dentin. Dent Mater 2002;18:269-275.

38. Moll K, Fritzenschaft A, Haller B. In vitro comparison of dentin bonding systems: Effect of testing method and operator. Quint Int 2004;35:845-852.

39. Rueggeberg FA. Substrate for adhesion testing to tooth structure-Review of the literature. Dent Mater 1991;7:2-10.

40. Dong CC, McComb D, Anderson JD, Tam L. Effect of mode of polymerization of bonding agent on shear bond strength of autocured resin composite luting cements. J Can Dent Assoc 2003;69:229-234.

41. Tantbirojn D, Cheng YS, Versluis A, Hodges JS, Douglas WH. Nominal shear or fracture mechanics in the assessment of composite dentin adhesion? J Dent Res 2000;79:41-48.

42. Tezvergil A, Lassila LV, Vallittu PK. The shear bond strength of bidirectional and random-oriented fibre-reinforced composite to tooth structure. J Dent 2005;33:509-516. Epub 2005 Mar 5.

43. Van Noort R, Noroozi S, Howard IC, Cardew G. A critique of bond strength measurements. J Dent 1989;17:61-67.

44. Versluis A, Tantbirojn D, Douglas WH. Why do shear bond tests pull out dentin? J Dent Res 1997;76:1298-1307.

45. DeHoff PH, Anusavice KJ, Wang Z. Three-dimensional finite element analysis of the bond strength of the shear bond test. Dent Mater 1995;11:126-131.

46. Phrukkanon S, Burrow MF, Tyas MJ. Effect of crosssectional surface area on bond strengths between resin and dentin. Dent Mater 1998;14:120-128.

47. Price RB, Doyle G, Murphy D. Effects of composite thickness on the shear bond strength to dentin. J Can Dent Assoc 2000;66:35-39.

48. Windley W 3rd, Ritter A, Trope M. The effect of short-term calcium hydroxide treatment on dentin bond strengths to composite resin. Dental Traumatol 2003;19:79-84.

49. Triolo PT, Swift EJ. Shear bond strengths of ten dentin adhesive systems. Dent Mater 1992;8:370-374.

50. Mason PN, Ferrari M, Cagidiaco MC, Davidson CL. Shear bond strength of four dentinal adhesives applied in vivo and in vitro. J Dent 1996;24:217-222.
51. Perdigao J May KN, Wilder AD, Lopes M. The effect of depth of dentin demineralization on bond strengths and morphology of the hybrid layer. Oper Dent 2000;25:186194.

52. Davidson CL, de Gee AJ, Feilzer A. The competition between the composite-dentin bond strength and the polymerization contraction stress. J Dent Res 1984;63:1396-1399.

53. Al Qahtani MQ, Platt JA, Moore BK, Cochran MA. The effect on shear bond strength of rewetting dry dentin with two desensitizers. Oper Dent 2003;28:287-296.

54. Price RB, Derand T, Andreou P, Murphy D. The effect of configuration factors, time and thermal cycling on resin to dentin bond strengths. Biomaterials 2003;24:1013-1021.

55. Watanabe LG, Marshall GW, Marshall SJ. Dentin shear strength: effects of tubule orientation and intratooth location. Dent Mater 1996;12:109-115.

56. Pashley DH, Sano H, Ciucchi B, Yoshiyama, Carvalho RM. Adhesion testing of dentin bonding agents: A review. Dent Mater 1995;11:117-125. 